\title{
How is dietary diversity related to haematological status of preschool children in Ghana?
}

\author{
Mahama Saaka and Sylvester Zakaria Galaa

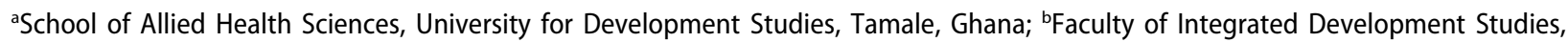 \\ University for Development Studies, Tamale, Ghana
}

\begin{abstract}
Background: The role of dietary diversity on blood biomarkers may be significant, but the evidence is limited.

Objective: This study assessed the association between dietary diversity and haematological status of children aged 6-59 months controlling for various known confounders.

Design: The analysis in this study is based on the 2014 Ghana Demographic and Health survey data.The study involved 2,388 pre-school children aged 6-59 months who constituted the subsample for anaemia assessment.

Results: The mean haemoglobin concentration $(\mathrm{Hb})$ was $10.2 \mathrm{~g} / \mathrm{dl} \pm 1.50$ (95\% Cl: 10.1 to 10.3), and anaemia prevalence $(\mathrm{Hb}<11 \mathrm{~g} / \mathrm{dl})$ among children aged 6-59 months was $66.8 \%$ (Cl: 63.7 to 69.8). In multivariable logistic regression analysis,continued breastfeeding [Adjusted odds ratio $(A O R)=1.9(95 \% \mathrm{Cl}: 1.19-2.91], 12-23$ months of age $(\mathrm{AOR}=2.4(95 \% \mathrm{Cl}: 1.40-3.98)$, having fever in last two weeks (AOR $=1.7(95 \% \mathrm{Cl}$ : $1.20-2.45$, birth interval $\leq 24$ months $(\mathrm{AOR}=1.9$ (1.20-2.84), and poorest wealth quintile (AOR $=2.6(95 \% \mathrm{Cl}: 1.48-4.48)$ were positively associated with anaemia.

Conclusion: The current study showed that factors other than poor dietary diversity predicted anaemia among children aged 6-59 months in Ghana.
\end{abstract}

ARTICLE HISTORY

Received 22 December 2016

Accepted 15 May 2017

\section{KEYWORDS}

Anaemia; minimum dietary diversity; haemoglobin; predictors of anaemia; Ghana Demographic and Health Survey

\section{Introduction}

Undernutrition, including micronutrient deficiencies, is a leading cause of maternal and child mortality and morbidity [1-5]. Of particular importance is anaemia, which remains one of the most intractable public health problems in many countries including Ghana. Anaemia is defined as a condition in which the number and size of red blood cells or haemoglobin concentration fall below an established cut-off, consequently impairing the capacity of the blood to transport oxygen around the body [6].

The global prevalence of anaemia among children under five is estimated to be about $47.4 \%$ [7]. In developing countries, it affects $46-66 \%$ of children aged under five years [8]. Anaemia has major consequences on socioeconomic development of a population [9] and it could be due to a complex interaction of many factors, including poor nutrition and health. Dietary diversity, defined as the number of different food groups consumed over a given reference period, has been identified as a useful measure for overall quality and nutrient adequacy of the diet that may influence blood formation. The dietary diversity score (DDS) is a recommended valid dietary assessment indicator that has been shown to reflect micronutrient intake among young children [10-12]. Consumption of foods from at least four food groups has been associated with a high likelihood of a child consuming at least one animalsource food and at least one fruit or vegetable, in addition to a staple food and, has been used to classify diets of children from developing countries $[13,14]$. Furthermore, dietary diversity is considered to be a key indicator in assessing the access, utilization and quality of diet of individuals or household [15].

In Ghana, where anaemia is of public health significance, very little is documented regarding the contribution of dietary factors to the haematological status of children. The effect of dietary diversity on blood biomarkers may be significant, but the evidence is limited. Furthermore, an association between dietary diversity and haematological status may be complicated by other factors including malarial infection and household 
socioeconomic status. This study therefore sought to determine the independent contribution of dietary diversity to the prevention of anaemia in children aged 6-59 months whilst controlling for potential confounding factors. We hypothesized that consumption of diversified diets would be associated with reduced prevalence of anaemia compared to nutrient-poor diets.

\section{Subjects and methods}

\section{Study area}

The study covered all the 10 administrative regions of Ghana. Ghana shares its northern boundary with Burkina Faso and its eastern boundary with the Republic of Togo and a western boundary with La Cote d'Ivoire.

\section{The study design, population and sampling}

This paper is based on further analysis of data which were collected in the 2014 Ghana Demographic and Health Survey (GDHS) carried out across all 10 regions. The community-based cross-sectional survey included 2388 pre-school children aged 6-59 months who constituted the sub-sample for anaemia assessment.

Each region was considered a stratum, from which representative probability samples were selected by Demographic and Health Survey (DHS) using stratified cluster sampling methodology. The DHS sample sizes were calculated to account for separate key indicators, and clusters were selected from the master frames in the first stage via the probability proportion to size (PPS) method [16]. Households were then selected from a sampling frame using a random systematic method.

\section{Data collection}

Study participants were then interviewed face-to-face by the investigators. Within each selected household, the caregiver responded to questions on anaemia prevention and treatment and expressed her knowledge and practices on anaemia. A pre-tested questionnaire was used to collect information including socio-demographic, infant and young child feeding (IYCF) practices, maternal knowledge, attitude, and practices on iron-rich foods, prevention and treatment of anaemia and child morbidity.

\section{Independent and dependent variables}

The main outcome variable for this study was the prevalence of anaemia ( $\mathrm{Hb}$ less than $11 \mathrm{~g} / \mathrm{dl}$ ). The independent variables were maternal, child and household characteristics, malarial infection, and child dietary intake. A brief description of main independent and dependent variables is as follows:

\section{Assessment of anaemia}

Haemoglobin levels were determined by using a portable HemoCue 301 photometer. Trained laboratory technicians drew capillary blood samples from the finger prick with a lancet after taking all aseptic precautions. The first drop of blood was wiped away using alcohol sterile wipes, and the next drop was placed into the Hemocue curvette for immediate testing of haemoglobin. According to the World Health Association (WHO), anaemia is defined as the presence of hemoglobin level of less than $11 \mathrm{~g} / \mathrm{dLin}$ children under five years of age [17]. Anaemia was further classified as mild $(9.0-10.9 \mathrm{~g} / \mathrm{dL})$, moderate $(7.0-8.9 \mathrm{~g} / \mathrm{dL})$ or severe $(<7.0 \mathrm{~g} / \mathrm{dL})$. Anaemia is said to be a severe public health problem when its prevalence is $40 \%$ or more in any group (all types of anemia) or when severe anaemia (haemoglobin $<7 \mathrm{~g} / \mathrm{dL}$ ) exceeds $2 \%$ [18].

\section{Measurement of dietary diversity}

The food groups in the DHS were regrouped to fall in line with the WHO recommended seven food groups used in defining children's minimum dietary diversity indicator as follows: (i) grains, roots and tubers; (ii) legumes and nuts; (iii) dairy products; (iv) flesh foods (meats/fish/poultry); (v) eggs; (vi) vitamin A-rich fruits and vegetables; and (vii) other fruits and vegetables [13].

Mothers were asked to recall the number of times, in the past 24 hours, a child had received anything to eat, aside from breast milk, including meals and snacks. The dietary diversity score therefore ranged from $0-7$ with minimum of 0 if none of the food groups is consumed, to 7 if all the food groups are consumed. WHO defined minimum dietary diversity as the proportion of children aged 6-23 months who received foods from at least four out of seven food groups in a 24 hour time period $[13,19]$. Traditionally, this concept had been applied to children 6-23 months but in this study, we extended to all children 6-59 months. We defined adequate dietary diversity as consumption of food from at least four different food groups $(\mathrm{DDS} \geq 4)$. 


\section{Socioeconomic and demographic factors}

Socioeconomic and demographic information was collected on mothers' age, marital status and highest level of education attained by the mothers. Household socioeconomic status was determined from the household wealth index. The household wealth index is a standardized asset-based score that is divided into quintiles [20]. Additional household variables included household residence (urban/rural) and household size.

\section{Other variables}

Mothers were asked if the children were breast feeding at the time of the survey. For morbidity experience, respondents were asked to recall if the child had experienced any diarrhoea or cough episode in the past seven days preceding the interview.

\section{Data processing and analysis}

Data were analysed using complex samples module for Windows in IBM-SPSS version 20. The analysis of data took into account the complex design of multi-stage cluster surveys. This was done in order to make statistically valid population inferences and computed standard errors from sample data. Sample weights were applied to each stratum to account for differences in population size in each (that is, weighted analysis).

Both bivariate and multivariate analyses were carried out to identify risk factors of anaemia. Association between anaemia and some risk factors in pregnancy was tested using chi-square and multivariable analysis of risk factors. Independent variables with $\mathrm{p}$ value less than 0.1 in bivariate analysis were entered into multivariable logistic regression model. $\mathrm{P}$ value less than 0.05 were taken as statistically significant and adjusted odds ratio with $95 \%$ confidence interval (CI) was used to measure association.

Analyses of association between haemoglobin concentration $(\mathrm{Hb})$ and other variables were carried out using bivariate and multivariate techniques. First, bivariate analyses for all the various risk factors were performed using chi-square $\left(\chi^{2}\right)$ tests for categorical variables and analysis of variance (ANOVA) for means of continuous variables.

\section{Ethical statement}

The analyses in this paper are based on secondary data obtained with permission from MEASURE DHS Organization and was downloaded from the Demographic and Health Surveys (DHS) online archive. DHS datasets are in the public domain and available to all registered users who have been granted access upon request. The original DHS data were collected with approval from the Inner City Fund (ICF) International's Institutional Review Board and national ethical guidelines. Information about objective of the study, procedures, potential risks and benefits was given to mothers before their children were enrolled to the study. Verbal informed consent was obtained before the household questionnaires were administered, and before blood was collected for anemia testing. An informed consent was read in the local language and a copy given to the household upon request. Those selected to give blood samples were informed of the general purpose, possible risks and benefits of the survey in their language. Participation in the survey was voluntary and participants' full right to refuse participation was explained.

\section{Results}

\section{Sociodemographic characteristics of the sample}

A total of 2388 children aged 6-59 months were involved in this analysis; $52.9 \%$ were male, and $47.1 \%$ were female. The mean age of the children was $31.5 \pm 15.3$ months. Majority of the respondents (51.3\%) had at least secondary education and 20.5\% fall within the poorest household wealth index. Petty trading and agricultural farming were the common occupations among the mothers. Table 1 displays the socio-demographic characteristics of the study sample.

\section{Prevalence of anaemia}

The mean haemoglobin concentration among the children studied was $10.2 \mathrm{~g} / \mathrm{dl} \pm 1.50$ (95\% CI: 10.1-10.3), and an overall prevalence of anaemia (Haemoglobin level $<11 \mathrm{~g} / \mathrm{dl}$ ) among children aged 6-59 months was $66.8 \%$ (CI: 63.7-69.8). In terms of severity, mild anaemia was $27.0 \%$ (95\% CI: 24.9-29.2), moderate anaemia was $37.4 \%$ (CI: 34.6-40.3) and severe anaemia was $2.4 \%$ (CI: $1.8-3.3$ ).

The prevalence of anaemia decreased with age and the highest level was in the Northern Region.

Overall, there was no gender difference for anaemia in the study sample. The proportion of children suffering from anaemia according to age group, gender and geographical location is shown in Table 2. 
Table 1. Sociodemographic characteristics of sample $(\mathrm{N}=2388)$.

\begin{tabular}{|c|c|c|}
\hline Characteristics & Frequency (n) & Percentage (\%) \\
\hline \multicolumn{3}{|l|}{ Age of children (months) } \\
\hline $6-11$ & 268 & 11.3 \\
\hline $12-23$ & 580 & 24.5 \\
\hline $24-35$ & 550 & 22.5 \\
\hline $36-47$ & 504 & 21.5 \\
\hline $48-59$ & 486 & 20.2 \\
\hline \multicolumn{3}{|l|}{ Gender of child } \\
\hline Male & 1246 & 52.9 \\
\hline Female & 1142 & 47.1 \\
\hline \multicolumn{3}{|l|}{ Educational level of mothers } \\
\hline No education & 865 & 28.9 \\
\hline Primary & 490 & 19.7 \\
\hline Secondary & 960 & 48.1 \\
\hline Higher & 73 & 3.2 \\
\hline \multicolumn{3}{|l|}{ Household wealth index } \\
\hline Poorest & 774 & 22.8 \\
\hline Poorer & 516 & 20.5 \\
\hline Middle & 448 & 20.0 \\
\hline Richer & 354 & 18.3 \\
\hline Richest & 296 & 18.4 \\
\hline \multicolumn{3}{|l|}{ Occupation of respondent } \\
\hline Not working & 381 & 16.8 \\
\hline Professional/technical/managerial & 86 & 4.0 \\
\hline Clerical & 13 & 0.6 \\
\hline Sales & 761 & 36.2 \\
\hline Agricultural - self-employed & 787 & 27.4 \\
\hline Agricultural - employee & 22 & 0.7 \\
\hline Services & 19 & 0.8 \\
\hline Skilled manual & 290 & 12.2 \\
\hline Unskilled manual & 28 & 1.4 \\
\hline
\end{tabular}

\section{Relationship between minimum dietary diversity and anaemia}

The relationship between dietary diversity and anaemia was investigated among children aged 6-59 months. The mean dietary diversity score (DDS) from seven food groups was $2.0 \pm 1.5$ (95\% CI: 1.9-2.1). Analysis of covariance (ANCOVA) showed that a very strong interaction existed between minimum dietary diversity and age group on mean $\mathrm{Hb}, \mathrm{F}(2,1373)=18.69, \mathrm{P}<0.001$. This meant that the association between dietary diversity and $\mathrm{Hb}$ varied according to age group and the interaction was greatest in the age group 48-59 months. Minimum dietary diversity was positively associated with mean $\mathrm{Hb}$ concentrations among children 6-23 months but it was negatively associated with $\mathrm{Hb}$ concentrations among children 48-59 months (Table 3a). Minimum dietary diversity was weakly associated with anaemia prevalence only among children 6-23 months (Table 3b).

\section{Analysis of haemoglobin levels based on the type of food groups consumption frequency among children of 6-59 months}

Analysis of haemoglobin levels based on the type of foods fed to the children aged 6-59 months is shown in Table 4. Continued breastfeeding was directly associated with reduced haemoglobin concentration. Consumption of staple food (cereals, roots and tubers) and vitamin A-rich fruits and vegetables in the past 24 hours was associated with reduced haemoglobin concentrations. Consumption of the other food groups in the past 24 hours prior to the study was not associated with haemoglobin concentration levels.

\section{Factors associated with anaemia}

Bivariate analyses were performed to assess association of sociodemographic and other factors with child anemia (Table 5). The overall prevalence of

Table 2. Prevalence of anaemia by age, gender and geographical location.

\begin{tabular}{|c|c|c|c|c|c|c|}
\hline Age (months) & Total no. & Mean $\mathrm{Hb}(\mathrm{g} / \mathrm{dL})$ & $\begin{array}{c}\text { Total anaemia } \\
(\mathrm{Hb}<11.0 \mathrm{~g} / \mathrm{dL}) \\
\mathrm{n}(\%)\end{array}$ & $\begin{array}{c}\text { Severe }(<7.0 \mathrm{~g} / \mathrm{dL}) . \\
\mathrm{n}(\%)\end{array}$ & $\begin{array}{c}\text { Moderate }(7.0-8.9 \mathrm{~g} / \mathrm{dL}) \\
\mathrm{n}(\%)\end{array}$ & $\begin{array}{c}\text { Mild }(9.0-10.9 \mathrm{~g} / \mathrm{dL}) \\
\mathrm{n}(\%)\end{array}$ \\
\hline $6-11$ & 268 & $9.8 \pm 1.5$ & $209(78.4)$ & $12(3.8)$ & $129(48.3)$ & $68(26.3)$ \\
\hline $12-23$ & 580 & $9.7 \pm 1.5$ & $460(76.9)$ & $27(4.3)$ & $284(47.9)$ & $149(24.7)$ \\
\hline $24-35$ & 550 & $10.3 \pm 1.5$ & $386(66.0)$ & $12(1.5)$ & $212(33.7)$ & $162(30.7)$ \\
\hline $36-47$ & 504 & $10.5 \pm 1.5$ & $323(61.6)$ & $10(1.8)$ & $168(32.0)$ & $145(27.4)$ \\
\hline $48-59$ & 486 & $10.7 \pm 1.4$ & $284(55.0)$ & $6(1.1)$ & $148(28.4)$ & $130(25.5)$ \\
\hline \multicolumn{7}{|l|}{ Gender } \\
\hline Male & 1246 & $10.2 \pm 1.5$ & $886(66.7)$ & $44(2.7)$ & $494(36.6)$ & $348(27.5)$ \\
\hline Female & 1142 & $10.2 \pm 1.5$ & $776(66.9)$ & $23(2.1)$ & $447(38.3)$ & $306(26.4)$ \\
\hline \multicolumn{7}{|l|}{ Region } \\
\hline Western & 247 & $10.2 \pm 1.6$ & $168(67.7)$ & $10(3.3)$ & 85 (34.6) & $73(29.8)$ \\
\hline Central & 253 & $9.9 \pm 1.5$ & $184(73.4)$ & $8(2.2)$ & $107(44.5)$ & $69(26.7)$ \\
\hline Greater Accra & 185 & $10.6 \pm 1.4$ & $111(58.4)$ & $2(1.3)$ & $53(28.3)$ & $56(28.8)$ \\
\hline Volta & 187 & $10.1 \pm 1.5$ & $131(70.7)$ & $4(2.1)$ & $75(41.3)$ & $52(27.3)$ \\
\hline Eastern & 206 & $10.3 \pm 1.4$ & $140(66.5)$ & $2(0.9)$ & 77 (37.6) & $61(28.0)$ \\
\hline Ashanti & 234 & $10.7 \pm 1.6$ & $123(54.1)$ & $5(2.0)$ & $59(27.3)$ & $59(24.8)$ \\
\hline Brong Ahafo & 284 & $10.4 \pm 1.6$ & $183(63.5)$ & $8(2.6)$ & 92 (31.4) & $83(29.5)$ \\
\hline Northern & 377 & $9.4 \pm 1.4$ & $320(84.5)$ & $14(3.7)$ & $217(57.8)$ & 89 (22.9) \\
\hline Upper East & 218 & $10.0 \pm 1.4$ & 159 (74.6) & $5(2.9)$ & $89(41.0)$ & $65(30.6)$ \\
\hline Upper West & 197 & $9.8 \pm 1.6$ & $143(73.6)$ & $9(7.5)$ & 87 (44.8) & 47 (21.4) \\
\hline
\end{tabular}


Table 3. (a) Relationship between minimum dietary diversity and mean $\mathrm{Hb}$ stratified by age of child. (b) Relationship between minimum dietary diversity and prevalence of anaemia stratified by age of child.

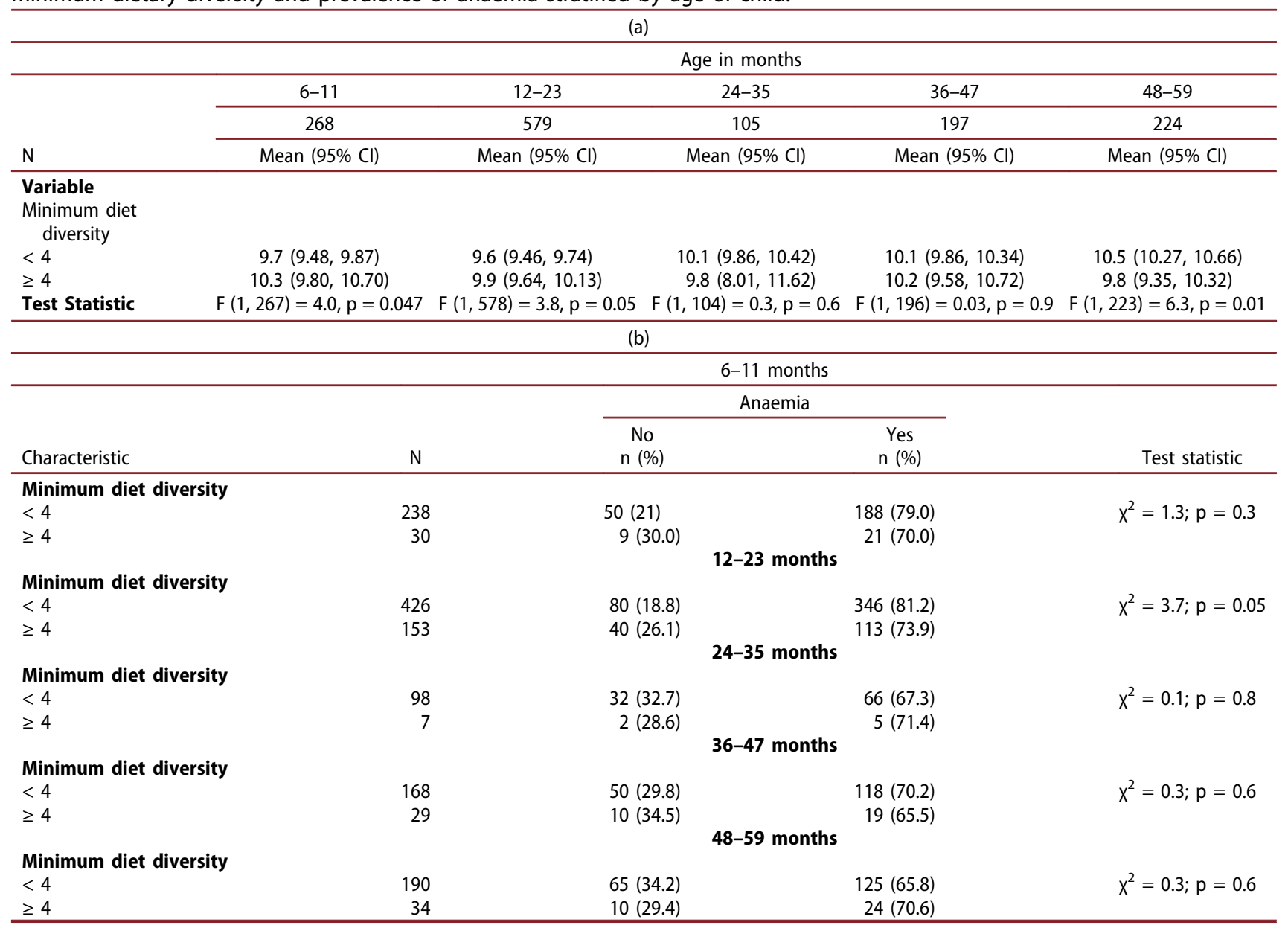

Table 4. Association between dietary factors and mean $\mathrm{Hb}$ among children 6-59 months.

\begin{tabular}{|c|c|c|c|c|c|c|}
\hline \multirow[b]{2}{*}{ Indicator } & \multirow[b]{2}{*}{$\mathrm{N}$} & \multirow[b]{2}{*}{ Mean $\mathrm{Hb}$} & \multirow[b]{2}{*}{$\begin{array}{c}\text { Std } \\
\text { deviation }\end{array}$} & \multicolumn{2}{|c|}{$\begin{array}{l}\text { 95\% Confidence interval for } \\
\text { mean }\end{array}$} & \multirow[b]{2}{*}{ Test Statistic } \\
\hline & & & & $\begin{array}{l}\text { Lower } \\
\text { bound }\end{array}$ & $\begin{array}{l}\text { Upper } \\
\text { bound }\end{array}$ & \\
\hline \multicolumn{7}{|c|}{ Is child currently breastfeeding? } \\
\hline Yes & 1290 & 9.8 & 1.5 & 9.76 & 9.92 & $F(1,2387)=89.6, p<0.001$ \\
\hline No & 1098 & 10.4 & 1.5 & 10.34 & 10.52 & \\
\hline \multicolumn{7}{|c|}{ Consumption of staple food (cereals, roots and tubers) } \\
\hline No & 371 & 10.1 & 1.5 & 9.96 & 10.27 & $F(1,1372)=10.63, p=0.001$ \\
\hline Yes & 1002 & 9.8 & 1.5 & 9.72 & 9.91 & \\
\hline \multicolumn{7}{|c|}{ Consumption of vitamin A-rich fruits and vegetables } \\
\hline No & 852 & 10.0 & 1.5 & 9.87 & 10.07 & $F(1,1372)=5.47, p=0.02$ \\
\hline Yes & 521 & 9.8 & 1.5 & 9.64 & 9.90 & \\
\hline \multicolumn{7}{|c|}{ Other vegetables } \\
\hline No & 1159 & 9.9 & 1.5 & 9.80 & 9.98 & $F(1,1372)=0.24, p=0.6$ \\
\hline Yes & 214 & 9.9 & 1.5 & 9.74 & 10.14 & \\
\hline \multicolumn{7}{|c|}{ Flesh meat (e.g. red meats, fish, etc.) } \\
\hline No & 775 & 9.9 & 1.6 & 9.83 & 10.05 & $F(1,1372)=1.4, p=0.2$ \\
\hline Yes & 598 & 9.8 & 1.5 & 9.72 & 9.96 & \\
\hline \multicolumn{7}{|l|}{ Eggs } \\
\hline No & 1170 & 9.9 & 1.5 & 9.79 & 9.96 & $F(1,1372)=1.4, p=0.2$ \\
\hline Yes & 203 & 10.0 & 1.4 & 9.81 & 10.21 & \\
\hline \multicolumn{7}{|l|}{ Lequmes } \\
\hline No & 1192 & 9.9 & 1.5 & 9.80 & 9.97 & $F(1,1372)=0.7, p=0.4$ \\
\hline Yes & 181 & 10.0 & 1.6 & 9.76 & 10.21 & \\
\hline \multicolumn{7}{|c|}{ Dairy products } \\
\hline No & 1357 & 9.9 & 1.5 & 9.82 & 9.98 & $\mathrm{~F}(1,1372)=2.0, \mathrm{p}=0.2$ \\
\hline Yes & 16 & 9.4 & 1.7 & 8.42 & 10.29 & \\
\hline
\end{tabular}


Table 5. Bivariate analysis of predictors of anaemia among children aged 6-59 months.

\begin{tabular}{|c|c|c|c|c|}
\hline \multirow[b]{2}{*}{ Characteristic } & \multirow[b]{2}{*}{$\mathrm{N}$} & \multicolumn{2}{|c|}{ Anaemia } & \multirow[b]{2}{*}{ Test statistic } \\
\hline & & $\begin{array}{c}\text { No } \\
\text { n (\%) }\end{array}$ & $\begin{array}{c}\text { Yes } \\
\text { n (\%) }\end{array}$ & \\
\hline \multicolumn{5}{|c|}{ Is child currently breastfeeding? } \\
\hline No & 1098 & $412(41.1)$ & $686(58.9)$ & \multirow[t]{2}{*}{$x^{2}=57.6 ; p<0.001$} \\
\hline Yes & 1290 & $314(26.4)$ & 976 (73.6) & \\
\hline \multicolumn{5}{|l|}{ Is child currently stunted? } \\
\hline No & 1875 & $623(36.2)$ & $1252(63.8)$ & \multirow[t]{2}{*}{$x^{2}=40.3 ; p<0.001$} \\
\hline Yes & 497 & $99(20.7)$ & $398(79.3)$ & \\
\hline \multicolumn{5}{|l|}{ Age (months) } \\
\hline $6-11$ & 268 & 59 (21.6) & $209(78.4)$ & \multirow[t]{5}{*}{$x^{2}=81.3 ; p<0.001$} \\
\hline $12-23$ & 580 & $120(23.1)$ & $460(76.9)$ & \\
\hline $24-35$ & 550 & $164(34.0)$ & $386(66.0)$ & \\
\hline $36-47$ & 504 & $181(38.8)$ & $323(61.2)$ & \\
\hline $48-59$ & 486 & $202(45.0)$ & $284(55.0)$ & \\
\hline \multicolumn{5}{|l|}{ Maternal education } \\
\hline None & 865 & $175(19.9)$ & $690(80.1)$ & \multirow{4}{*}{$x^{2}=100.1 ; p<0.001$} \\
\hline Primary & 490 & $145(31.7)$ & $345(68.3)$ & \\
\hline Secondary & 960 & $366(40.3)$ & $594(59.7)$ & \\
\hline Higher & 73 & $40(56.2)$ & $33(43.8)$ & \\
\hline \multicolumn{5}{|l|}{ Household wealth index } \\
\hline Poorest & 774 & $156(19.2)$ & $618(80.8)$ & \multirow{5}{*}{$x^{2}=143.6 ; p<0.001$} \\
\hline Poorer & 516 & $127(23.4)$ & 389 (76.6) & \\
\hline Middle & 448 & $155(36.7)$ & $293(63.3)$ & \\
\hline Richer & 354 & $131(39.9)$ & $223(60.1)$ & \\
\hline Richest & 296 & $157(51.0)$ & $139(49.0)$ & \\
\hline \multicolumn{5}{|l|}{ Religion } \\
\hline Christianity & 1676 & $577(36.6)$ & $1099(63.4)$ & \multirow[t]{3}{*}{$x^{2}=42.0 ; p<0.001$} \\
\hline Islam & 519 & $118(26.0)$ & $401(74.0)$ & \\
\hline African traditional religion & 193 & $31(15.7)$ & $162(84.3)$ & \\
\hline \multicolumn{5}{|l|}{ Type of place of residence } \\
\hline Urban & 958 & $357(40.5)$ & $601(59.5)$ & \multirow[t]{2}{*}{$x^{2}=48.9 ; p<0.001$} \\
\hline Rural & 1430 & $369(27.0)$ & $1061(73.0)$ & \\
\hline \multicolumn{5}{|l|}{ Place of delivery } \\
\hline Home delivery & 749 & $148(21.4)$ & $601(78.6)$ & \multirow[t]{2}{*}{$x^{2}=54.8 ; p<0.001$} \\
\hline Institutional delivery & 1639 & $578(37.5)$ & $1061(62.5)$ & \\
\hline \multicolumn{5}{|l|}{ Classification of ANC visits } \\
\hline$<4$ & 218 & $37(17.3)$ & $181(82.7)$ & $x^{2}=22.2 ; p=0.001$ \\
\hline$\geq 4$ & 1491 & $466(34.0)$ & $1025(66.0)$ & \\
\hline Anaemia status of mothe & & & & \\
\hline No & 1329 & $478(38.1)$ & $851(61.9)$ & \\
\hline Yes & 1041 & $242(26.7)$ & $799(73.3)$ & $x^{2}=34.6 ; p<0.001$ \\
\hline Parity of mother & & & & \\
\hline $1-2$ & 833 & $281(37.6)$ & $552(62.4)$ & $x^{2}=16.1 ; p=0.008$ \\
\hline $3-4$ & 815 & $251(33.0)$ & $564(67.0)$ & \\
\hline$>4$ & 740 & $194(28.1)$ & $546(71.9)$ & \\
\hline Diarrhoea in the past tw & & & & \\
\hline No & 2072 & $657(34.1)$ & $1415(65.9)$ & $x^{2}=6.3, p=0.07$ \\
\hline Yes & 316 & $69(26.8)$ & $247(73.2)$ & \\
\hline Had fever in last two we & & & & \\
\hline No & 1992 & $643(35.4)$ & $1349(64.6)$ & $x^{2}=28.8 ; p<0.001$ \\
\hline Yes & 396 & $83(21.0)$ & $313(79.0)$ & \\
\hline
\end{tabular}

anaemia fell with age and was significantly associated with religion of the mother and whether or not the child was breastfeeding at the time of the survey. A smaller proportion of still-breastfeeding than nonbreastfeeding children consumed the recommended minimum dietary diversity (16.5 versus $44.0 \%)$ $\left(\chi^{2}=73.7 ; \mathrm{P}<0.001\right)$.

Christians had a lower prevalence of anaemia than moslems and traditionists. Both educational level and household wealth quintiles were negatively associated with anaemia.

\section{Multivariable analysis of the determinants of anaemia among children 6-59 months}

In bivariate analyses, stunting and minimum dietary diversity were associated with anaemia but they did not remain in a regression model. Multivariate logistic regression analysis showed that continued breastfeeding $($ AOR $=1.9(95 \%$ CI: 1.19-2.91), 24-35 months of age (AOR $=2.5$ (95\% CI: $1.64-$ $3.83), 12-23$ months of age $(\mathrm{AOR}=2.4(95 \% \mathrm{CI}$ : 1.40-3.98), having fever in last two weeks $(\mathrm{AOR}=1.7$ (95\% CI: 1.20-2.45), anaemic mother 
Table 6. Predictors of anaemia among children stratified by age groups (multivariable analysis).

\begin{tabular}{|c|c|c|c|}
\hline $\begin{array}{l}\text { Age group (months) } \\
\text { Variable }\end{array}$ & $\begin{array}{c}6-23 \\
\text { AOR }(95 \% \mathrm{Cl})\end{array}$ & $\begin{array}{c}24-59 \\
\text { AOR }(95 \% \mathrm{Cl})\end{array}$ & $\begin{array}{c}6-59 \\
\text { AOR(95\% Cl) }\end{array}$ \\
\hline \multicolumn{4}{|l|}{ Minimum } \\
\hline$\geq 4$ & Reference & Reference & Reference \\
\hline$<4$ & Not significant in final model & Not significant in final model & Not significant in final model \\
\hline \multicolumn{4}{|c|}{ Household wealth index } \\
\hline Poorest quintile & $1.7(0.71,4.26)$ & $3.0(1.48,6.05)^{* *}$ & $2.6(1.48,4.48)^{* * *}$ \\
\hline Poorer & $2.0(0.84,4.57)$ & $2.5(1.29,4.81)^{* *}$ & $2.4(1.43,4.03)^{* * *}$ \\
\hline Middle & $1.2(0.51,2.76)$ & $2.1(1.10,3.95)^{*}$ & $1.9(1.15,3.20)^{* *}$ \\
\hline Richer & $2.2(0.99,4.96)$ & $2.6(1.42,4.90)^{* *}$ & $2.7(1.66,4.46)^{* * *}$ \\
\hline Richest & Reference & Reference & Reference \\
\hline \multicolumn{4}{|l|}{ Is mother anaemic? } \\
\hline No & Reference & Reference & Reference \\
\hline Yes & $1.6(1.07,2.50)^{*}$ & $1.5(1.05,2.02)^{*}$ & $1.6(1.21,2.04)^{* * *}$ \\
\hline \multicolumn{4}{|c|}{ Currently breastfeeding? } \\
\hline No & Reference & Reference & Reference \\
\hline Yes & $1.4(0.80,2.41)$ & $3.0(1.38,6.54)^{* *}$ & $1.9(1.19,2.91)^{* * *}$ \\
\hline \multicolumn{4}{|l|}{ Type of toilet facility } \\
\hline No toilet facility & $1.8(1.02,3.18)^{*}$ & $1.4(0.89,2.14)$ & $1.5(1.05,2.11)^{*}$ \\
\hline Flush toilet & $0.8(0.38,1.63)$ & $1.2(0.67,2.06)$ & $1.0(0.63,1.53)$ \\
\hline \multirow{2}{*}{\multicolumn{4}{|c|}{ Fever in the past two weeks? }} \\
\hline & & & \\
\hline No & Reference & Reference & Reference \\
\hline Yes & $2.9(1.45,5.95)^{* *}$ & $1.40(0.92,2.12)$ & $1.7(1.20,2.45)^{* *}$ \\
\hline \multicolumn{4}{|c|}{ Frequency of ANC visits } \\
\hline $0-3$ & $1.7(0.80,3.73)$ & $1.41(0.82,2.43)$ & $1.5(1.01,2.39)^{*}$ \\
\hline At least 4 & Reference & Reference & Reference \\
\hline \multicolumn{4}{|l|}{ Place of delivery } \\
\hline Home delivery & $1.9(1.08,3.26)^{*}$ & $1.2(0.77,1.73)$ & $1.4(1.04,2.0)^{*}$ \\
\hline Institutional delivery & Reference & Reference & Reference \\
\hline \multicolumn{4}{|c|}{ Birth interval in months } \\
\hline$>24$ & Reference & Reference & Reference \\
\hline Up to 24 & $2.5(1.17,5.39)^{* *}$ & $1.7(1.02,2.93)^{*}$ & $1.9(1.20,2.84)^{* *}$ \\
\hline
\end{tabular}

*significant at $p<0.05 ;{ }^{* *}$ significant at $p<0.01 ;{ }^{* * *}$ significant at $p<0.001$.

AOR ( $95 \% \mathrm{Cl})$ : Adjusted odds ratio at $95 \%$ confidence level.

$(\mathrm{AOR}=1.6(95 \% \mathrm{CI}: 1.21-2.04)$, birth interval $\leq 24$ months $(\mathrm{AOR}=1.9(1.20-2.84)$, Home delivery $(\mathrm{AOR}=1.4(95 \% \mathrm{CI}: 1.04-2.00)$, $\mathrm{ANC}$ attendance $<<4$ (AOR $=1.5$ (95\% CI: 1.01-2.39), no toilet facility $(\mathrm{AOR}=1.5$ (95\% CI: $1.05-2.11)$ and poorest wealth quintile $(\mathrm{AOR}=2.6(95 \% \mathrm{CI}$ : 1.48-4.48) were positively associated with anemia (Table 6). The set of variables could explain only $17 \%$ of the variation in anaemia in the population (Nagelkerke R square $=0.170)$ which suggest many more factors other than those measured in this study are responsible for anaemia.

\section{Discussion}

The study is the first to investigate the potential role dietary diversity plays in haematological status of children using a nationally representative sample in Ghana. The analyses sought to assess the association between dietary diversity to haematological status of children aged 6-59 months whilst controlling for potential confounding factors including malarial infection.
The most consistent determinants of anaemia were child's age, continued breastfeeding, poverty, having fever, anaemic mother, birth interval $\leq 24$ months, home delivery and having no access to toilet facility. Genetic characteristics and micronutrient interactions may impair normal haemoglobin synthesis but these were not assessed in this survey.

\section{Prevalence of anaemia}

The prevalence of anaemia among children aged 6-59 months was $66.8 \%$. Anaemia is a public health problem when more than $5 \%$ of the population is anaemic, a significant public health problem in need of immediate action when prevalence exceeds $20 \%$, and a severe public health problem when prevalence exceeds $40 \%$ [18]. The survey findings corroborate past research that in developing countries, anaemia affects $46-66 \%$ of children aged under five years [18].

Most of the children in this study had anaemia of mild to moderate severity with very few being severely anaemic. According to the WHO, the most common cause of high prevalence of anemia (above $40 \%$ ) is the lack of dietary iron, which is related to the low 
consumption of this micronutrient and/or to the high ingestion of inhibitors of iron absorption [21]. Iron deficiency is the most common preventable nutritional deficiency in the world, especially among infants and young children in developing countries [22] and yet it is one of the most intractable public health problems in most countries.

\section{Relationship between dietary diversity and anaemia}

Evidence from the analyses of the data showed that there was an interaction between minimum dietary diversity and age group on mean $\mathrm{Hb}$. This meant the association between dietary diversity and $\mathrm{Hb}$ varied according to age group. In bivariate analyses, minimum dietary diversity was positively associated with mean $\mathrm{Hb}$ concentrations among children 6-23 months but it was negatively associated with $\mathrm{Hb}$ concentrations among children 48-59 months. Minimum dietary diversity was weakly associated with reduced prevalence of anaemia only among children 6-23 months although this relationship disappeared in the multiple regression model. This apparent lack of association may be due to the fact that the consumption of ironrich foods was generally low in the study sample. Consequently, statistical power to detect significant associations between anaemia and dietary diversity was low. It should be noted, however, that diet is only one of the protective factors against anaemia and dietary diversity may not be the most pressing constraint in the Ghanaian population where infections are also common.

The relationship between dietary diversity and anaemia has been inconclusive. Although intake of diversified foods is expected to protect against anaemia, some other studies have reported a lack of association between dietary diversity and anaemia, especially in environments where many other factors other than diet exposure can increase the risk of getting anaemia. Neither minimum dietary diversity as a composite index, nor intake of specific food groups (e.g. grains, vegetables, flesh food and eggs) is reported to be unrelated to anaemia in several studies [23-26].

Dietary diversity at the individual level is a measure of quality of the diet. That is, the more diversified a child's diet is, the larger the variety of nutrients he/she receives which enhance his/her health and nutrition. The number of different food groups consumed therefore better reflects a quality diet. Children who consume, for example, an average of four different food groups implies that their diets offer some diversity in both macro- and micronutrients intakes.

It must be noted that, although no strong associations were found between anaemia and dietary diversity in the present study, at least one study has shown significant association between dietary diversity and anaemia in preschool children [27].

We also noted in our study that household wealth index associated positively with minimum dietary diversity (MDD) (chi-square $=21.2, \mathrm{p}<0.001$ ) and once household wealth index is in the model, the effect of MDD becomes insignificant. It is possible wealth index could be replacing the role of MDD and so studies that have not controlled for wealth index could conclude that MDD is negatively associated with anaemia.

\section{Dietary intake of children and prevalence of anaemia among children of 6-59 months}

Breast milk generally is low in iron, since iron store in breast milk can only sustain the child from birth to 6 months [14]. This means that children who do not receive adequate complementary foods rich in iron stand a greater risk of anaemia. Micronutrient deficiency is considered one of the main causes of anaemia [28]. Iron deficiency is by far the major cause of nutritional anaemia worldwide [28].

Continued breastfeeding was directly associated with poor dietary diversity score and reduced haemoglobin concentration. Several studies have earlier reported of the negative association between continued breastfeeding and the risk of anaemia and poor complementary feeding [11,29-32].

Increased dietary diversity is associated with a higher likelihood of meeting children's recommended nutrient intake levels [10] that may include important nutrients such as iron and zinc. It is not surprising that continued breastfeeding children were more likely to be anaemic because of the associated poor diets. The negative relationship between breast feeding and adequate DDS has been reported in other countries $[33,34]$ and has policy implications for IYCF promotion efforts. Breastfeeding women should be specially targeted for improved dietary practices. Breastfeeding mothers may have the erroneous impression that their children are having adequate dietary intake. It is possible that such mothers were not aware of the importance of adequate complementary foods in meeting young children's nutritional needs. It is well documented that although breast milk contributes significantly to the total nutrient intake of children within 6-24 months of age, it may not be an adequate 
source of micronutrients such as iron, zinc and vitamin A for older children, especially in the presence of maternal deficiency $[6,35]$.

Cereals, roots and tubers were the predominant foods consumed and these types of food contain a high content of iron inhibitors such as polyphenols and provide low amounts of bioavailable iron [36,37]. This perhaps explains the negative association between consumption of these foods and $\mathrm{Hb}$ concentrations observed in this study.

Nutritional problems, including anaemia, are common in poor populations, since their diets are predominantly based on starchy staples [38] and these plant-based diets are low in micronutrient contents, and high in phytate and dietary fibre which inhibit the absorption of micronutrients such as iron [39].

From the analysis we found that children who were breastfeeding were more likely to be anaemic as compared to their counterparts who were not breastfeeding. This finding may be explained by the fact that, breast milk alone is inadequate to meet the nutritional needs of children aged 6-24 months but rather a combination of breastfeeding and adequate complementary foods is needed [40].

According to the results of the current survey, it appears that breastfeeding children aged 6-23 months were not getting adequate complementary foods. In the study sample, the dietary diversity score of such children was significantly lower than their counterparts who were not breastfeeding. All these point to the fact that breastfeeding children are at greater risk of being fed on sub-optimal complementary feeding regime and this has great potential of compromising their iron status.

\section{Determinants of anaemia among children 6-59 months}

In the study, young children were more likely to be anemic compared with older children. The overall prevalence of anaemia was inversely related to age and the greatest prevalence occurred among the 6-11 months age group. This finding is consistent with the literature which maintains that anaemia is common among children around the time of the growth spurt, especially between the ages of 6 and 24 months [36,41-43]. The child's physical development is rapid during this period, thereby requiring an expanded blood volume. At this stage of growth, if the iron storage from the maternal source is depleted then diet becomes a vital source for iron as a result [28]. This means that if exogenous iron is deficient, anaemia can occur easily [23].

Several other studies in many countries including India and Burma have reported a similar effect of the age of the child on anaemia [31,32,44]. Younger children are most vulnerable to anaemia perhaps because they require a relatively higher iron intake to meet the demand of rapid growth.

In addition, most complementary foods do not supply enough iron for children aged 6-11 months [45]. So, iron-rich complementary foods need to be introduced to children at six months, when maternal iron stores are exhausted and after exclusive breastfeeding [45]. Additionally, some infectious diseases including malaria and diarrhoea may have greater effect on such children, so preventing and treating these infections timely is also important for childhood anemia in this age.

Evidence from our analysis showed children from families of poorest wealth quintiles were more likely to be anaemic than children of the richest wealth quintile. The finding is in line with studies conducted in other countries including Brazil [32] and Bangladesh [27,46]. Poor household economic status might constrain families to access available health services such as antenatal care, decent toilet facilities and the power to purchase diversified and nutrient rich foods, all of which are risk factors to anaemia.

Stunted children were more likely to be anaemic than their counterparts. This finding is similar to studies conducted in many countries including Ethiopia, Bangladesh, Brazil and Burma [3,4,23,27]. The reverse equally holds whereby anaemic children are more likely to be undernourished [4] because a low hemoglobin level negatively affects linear growth [47].

Consistent with other studies [23,46], maternal anaemia was associated with anemia in the children. This association could be partly be explained on the basis that all family members shared the same socioeconomic environment [23].

Our results also showed that prevalence of anaemia among children whose mothers attended antenatal care at least four times was significantly lower and were less likely of becoming anaemic. This is understandable because access to quality healthcare services affords women the opportunity to take advantage of essential preventive measures (nutrition education, promotion of use of insecticide treated nets) thereby ensuring that children are healthy. The finding supports previous studies that have reported the association between infrequent prenatal consultations and the presence of anaemia $[46,48,49]$.

From previous studies, we know that infectious diseases were a common cause of anemia, and anemic children were more susceptive to infectious diseases [50]. Consistent with these findings, having fever in the past two weeks prior to the study was found to be positively related to anemia in this study [51]. Sick 
children are known to have poor appetite and hence a low dietary intake [52].

In the present study, the children from households without a toilet facility were more likely to have anaemia than their counterparts with at least a pit latrine. Other studies conducted among preschool children elsewhere have highlighted the potential effect of poor water, sanitation and hygiene (WASH) conditions of the physical environment on nutritional status and anaemia [51,53]. Poor sanitation conditions are most likely to be prevalent in environments where there are no decent toilet facilities and such conditions are associated with greater numbers of infectious and parasitic diseases, which in turn can bring about diminishing haemoglobin levels, through poor intake of food and absorption of available nutrients including iron and zinc. Low intake of iron-rich foods and diminished nutrient absorption caused by changes to the gastrointestinal epithelium of infected children can significantly contribute towards anaemia.

The set of predictors of anaemia identified in this study could explain only $17 \%$ of the variation in anaemia in the population, which suggest many more factors other than those measured in this study are responsible for anaemia.

\section{Conclusion and recommendations}

The prevalence of anaemia was of public health significance according to the WHO cut-off points. In bivariate analyses, minimum dietary diversity was positively associated with mean $\mathrm{Hb}$ concentrations among children 6-23 months but it was negatively associated with $\mathrm{Hb}$ concentrations among children 48-59 months. Similarly, minimum dietary diversity was weakly associated with reduced prevalence of anaemia only among children 6-23 months although this relationship disappeared in the multiple regression model.

The current study showed that factors other than poor dietary diversity predicted anaemia among children aged 6-59 months in Ghana. Poverty, child having reported to have high temperature (fever) in the past two weeks, age of the child, continued breastfeeding, anaemic mother, birth interval $\leq 24$ months, home delivery and having no access to toilet facility were positively associated with anemia. An integrated approach is required to address the multiple risks. Measures to control anaemia should therefore include alleviating general poverty, empowering and educating women, improving personal and environmental hygiene, improving access to antenatal care services and controlling frequent births.

\section{Limitations of the study}

Although the study used nationally representative data, there were still some limitations that need to be noted and taken into consideration in the interpretation of the of the study results. The cross-sectional nature of this study does not ensure causality between independent variables and anaemia. Anaemia status from the study group was determined on the basis of haemoglobin concentrations, which are not the best indicator compared to serum ferritin. Then, also, recall of food intake in the past 24 hours cannot best reflect usual food intake.

It was also not possible to measure all the potential causes of anaemia (e.g. infections, genetic characteristics and micronutrient interactions may impair normal haemoglobin synthesis). This was manifested in the fact that all of the risk factors studied could only explained $17 \%$ of the variation in the outcome. There is therefore the need to conduct a longitudinal study, which may also allow for measurement of a longer exposure to dietary intake.

\section{Acknowledgements}

The authors would like to gratefully acknowledge the contribution of the Ghana Statistical Service (GSS), the Ghana Health Service (GHS) and the National Public Health Reference Laboratory (NPHRL) for implementing the 2014 Ghana Demographic and Health Survey. ICF International provided technical assistance through the DHS Program.

We are thankful to the data collection team members for their hard work and commitment. The data could not have been obtained without the cooperation and support of mothers and caregivers who took time off from their busy schedules to respond to the interviewers. Their involvement and cooperation is highly appreciated.

\section{Authors' contribution}

MS did the analysis and interpretation of data and was deeply involved in drafting the manuscript and revising it critically for important intellectual content. SG assisted in data retrieval, manuscript writing and critically commented on the draft manuscript. All authors gave final approval of the version to be published.

\section{Disclosure statement}

No potential conflict of interest was reported by the authors.

\section{References}

[1] Horton R. Maternal and child undernutrition: an urgent opportunity. Lancet. 2008;371(9608):179.

[2] Black RE, Allen LH, Bhutta ZA, et al. Maternal and child undernutrition: global and regional exposures and health consequences. Lancet. 2008;371:243-260. 
[3] Grantham-McGregor S, Cheung YB, Cueto S, et al. Developmental potential in the first 5 years for children in developing countries. Lancet. 2007;369:60-70.

[4] Olofin I, McDonald CM, Ezzati M, et al. Associations of suboptimal growth with all-cause and cause-specific mortality in children under five years: a pooled analysis of ten prospective studies. Plos One. 2013;8:e64636.

[5] Black RE, Victora CG, Walker SP, et al. Maternal and child undernutrition and overweight in low-income and middle-income countries. Lancet. 2013;382:427-451.

[6] Jelliffe DB, Jelliffe EF. The volume and composition of human milk in poorly nourished communities. A review. Am J Clin Nutr. 1978;31(3):492-515.

[7] Benoist BD, McLean E, Egll I, et al. Worldwide prevalence of anemia 1993-2005: WHO global database on anemia. Geneva: World Health Organization; 2008.

[8] Lozoff B, Georgieff MK. Iron deficiency and brain development. Semin Pediatr Neurol. 2006;13(3):158-165.

[9] World Health Organization. Global burden of diseases 2004 update. Geneva: World Health Organization; 2008.

[10] Moursi MM, Arimond M, Dewey KG, et al. Dietary diversity is a good predictor of the micronutrient density of the diet of 6- to 23-month-old children in Madagascar. J Nutr. 2008;138(12):2448-2453.

[11] Steyn N, Nel J, Nantel G, et al. Food variety and dietary diversity scores in children: are they good indicators of dietary adequacy? Public Health Nutr. 2007;9(5):644-650.

[12] Arimond M, Ruel MT. Dietary diversity, dietary quality, and child nutritional Status: evidence from eleven demographic and health surveys. Washington (DC): FANTA Project III; 2004.

[13] WHO, UNICEF, USAID, FANTA, AED, UC DAVIS, IFPRI. Indicators for assessing infant and young child feeding practices part 2: measurement. Geneva: The World Health Organization; 2010.

[14] Dewey K, Arimond M, Ruel M. Working group on infant and young child feeding indicators. Developing and validating simple indicators of dietary quality of infants and young children in developing countries: additional analysis of 10 data sets. Washington (DC): FANTA Project III; 2007.

[15] Kennedy G, Ballard T, Dop M. Guidelines for measuring individual and household dietary diversity. Rome: Nutrition and Consumer Protection Division, FAO; 2011.

[16] ICF International. Demographic and Health Survey: sampling and household listing manual. Vol. 2014. Calverton (MD): USA ICF International; 2012.

[17] Benoist BD, McLean E, Egll I, et al. Worldwide prevalence of anaemia 1993 -2005: WHO global database on anaemia. Geneva: WHO; 2008.

[18] WHO. Worldwide prevalence of anemia 1993-2005: WHO global database of anaemia. Geneva: World Health Organization; 2008.

[19] World Health Organization. Indicators for assessing infant and young child feeding practices part 1 definitions. Washington (DC): World Health Organization, Dept. of Child and Adolescent Health and Development; 2007.

[20] Rustein SO, Johnson K. The DHS wealth index. Calverton (MD): Micro International; 2004. (DHS comparative reports no 6).
[21] Neumann C, Bwibo N, Sigman M. Final report phase II (1992) functional implications of malnutrition, Kenya. Nutrition CRSP. Los Angeles: University of California (CA); 1992.

[22] Iannotti L, Barron M, Roy D. Animal Source Food Consumption and Nutrition Among Young Children in Indonesia: Preliminary Analysis for Assessing the Impact of HPAI on Nutrition. Africa/Indonesia Team Working Paper No. 17, 40 pp; 2008.

[23] Zhao A, Zhang Y, Peng Y, et al. Prevalence of anemia and its risk factors among children 6-36 months old in Burma. Am J Trop Med Hyg. 2012;87(2):306-311.

[24] Mikki N, Abdul-Rahim HF, Stigum H, et al. Anaemia prevalence and associated sociodemographic and dietary factors among Palestinian adolescents in the West Bank. East Mediterr Health J. 2011;17:208-217.

[25] Halileh S, Gordon NH. Determinants of anemia in preschool children in the occupied Palestinian territory. J Trop Pediatr. 2006;52:12-18.

[26] McDonald CM, McLean J, Kroeun H, et al. Household food insecurity and dietary diversity as correlates of maternal and child undernutrition in rural Cambodia. Eur J Clin Nutr. 2015;69(2):242-246.

[27] Woldie H, Kebede Y, Tariku A. Factors associated with anemia among children aged 6-23 months attending growth monitoring at Tsitsika Health Center, WagHimra Zone, Northeast Ethiopia. J Nutr Metab. 2015; doi:10.1155/2015/928632

[28] Allen LH, Gillepsie S. What works? A review of the efficacy and effectiveness of nutrition interventions. Geneva: Asian Development Bank (ADB); 2001. (ACC/SCN nutrition and development series, no 5).

[29] Murphy SP, Allen LH. Nutritional importance of animal source foods. J Nutr. 2003;133:3932S-3935S.

[30] Scrimshaw N. The consequences of hidden hunger for individuals and societies. Food Nutr Bull. 1994;15:13-24.

[31] Allen L, Backstrand J, Chavez A, et al. People cannot live by tortillas alone: the results of the Mexico nutrition CRSP. Storrs (CT): University of Connecticut; 1992.

[32] Lozoff B, Jimenez E, Wolf AW. Long-term developmental outcome of infants with iron deficiency. N Engl J Med. 1991;325:687-694.

[33] Gewa CA, Leslie TF. Distribution and determinants of young child feeding practices in the East African region: demographic health survey data analysis from 2008-2011. J Health, Popul Nutr. 2015;34:6.

[34] Patel A, Pusdekar Y, Badhoniya N, et al. Determinants of inappropriate complementary feeding practices in young children in India: secondary analysis of National Family Health Survey 2005-2006. Matern Child Nutr. 2012;8 Suppl 1:28-44.

[35] Lönnerdal B. Effects of maternal dietary intake on human milk composition. J Nutr. 1986;116(4):499-513.

[36] Fosu MO, Frimpong FO, Arthur MO. Factors associated with haemoglobin prevalence among Ghanaian children aged 6 - 59 months. J Biology, Agric Healthc. 2014;4 (2):132-140.

[37] Givens DI, Shingfield KJ. Foods derived from animals: the impact of animal nutrition on their nutritive value and ability to sustain long-term health. Nutr Bull. 2004;29:325-332. 
[38] Habtemariam K, Ayalew W, Habte GZ, et al. Enhancing the role of livestock production in improving nutritional status of farming families: lessons from a dairy goat development project in Eastern Ethiopia. Livestock Res Rural Dev. 2003;15 (6): Available at: http://www.lrrd. org/lrrd15/6/kass156.htm.

[39] Ayalew W, Gabriel ZW, Habtemariam K. Reducing vitamin A deficiency in Ethiopia: linkages with a women-focused dairy goat farming project. Washington (DC): International Center for Research on Women, Opportunities for Micronutrients Interventions; 1999. (Report no 4).

[40] Dacey SJ, Travers FJ. Human development across the lifespan. 5th ed. New York (NY): McGraw Hill; 2004.

[41] Allen LH, Penland JG, Boy E, et al. Cognitive and neuromotor performance of Guatemalan schoolers with deficient marginal and normal plasma vitamin B-12. Faseb J. 1999;13:544.

[42] Gibson RS, Hotz C. Dietary diversification/modification strategies to enhance micronutrient content and bioavailability of diets in developing countries. Br J Nutr. 2001;85(suppl. S2):S159-S166.

[43] Kemmer TM, Bovill ME, Kongsomboon W, et al. Iron deficiency is unacceptably high in refugee children from Burma. J Nutr. 2003;133:4143-4149.

[44] Hambidge M. Human zinc deficiency. J Nutr. 2000;130:1344S-1349S.

[45] WHO. Expert committee on physical status: the use and interpretation of anthropometry: report of a WHO expert committee. Geneva: World Health Organization; 1995.
[46] Leal LP, Filho MB, de Lira PIC, et al. Prevalence of anemia and associated factors in children aged 6-59 months in Pernambuco, Northeastern Brazil. Rev Saude Publica. 2011;45(3):457-466.

[47] Soliman AT, Al Dabbagh MM, Habboub AH, et al. Linear growth in children with iron deficiency anemia before and after treatment. J Trop Pediatr. 2009;55 (5):324-327.

[48] Osório MM, Lira PIC, Ashworth A. Factors associated with $\mathrm{Hb}$ concentration in children aged 6-59 months in the State of Pernambuco, Brazil. Br J Nutr. 2004;91 (2):307-315.

[49] Agho KE, Dibley MJ, D'Este C, et al. Factors associated with haemoglobin concentration among Timor-Leste children aged 6-59 months. J Health Popul Nutr. 2008;26(2):200-209.

[50] Brown DL. Solutions exist for constraints to household production and retention of animal food products. J Nutr. 2003;133:4042S-4047.

[51] Adish AA, Esrey SA, Gyorkos TW, et al. Risk factors for iron deficiency anaemia in preschool children in northern Ethiopia. Public Health Nutr. 1998;2(3):243-252.

[52] Lawless JW, Latham M, Stephenson LS, et al. Iron supplementation improves appetite and growth in anemic Kenyan primary school children. J Nutr. 1994;124:645-654.

[53] Ngure FM, Reid BM, Humphrey JH, et al. Water, sanitation, and hygiene (WASH), environmental enteropathy, nutrition, and early child development: making the links. Ann N Y Acad Sci. 2014;1308:118-128. 